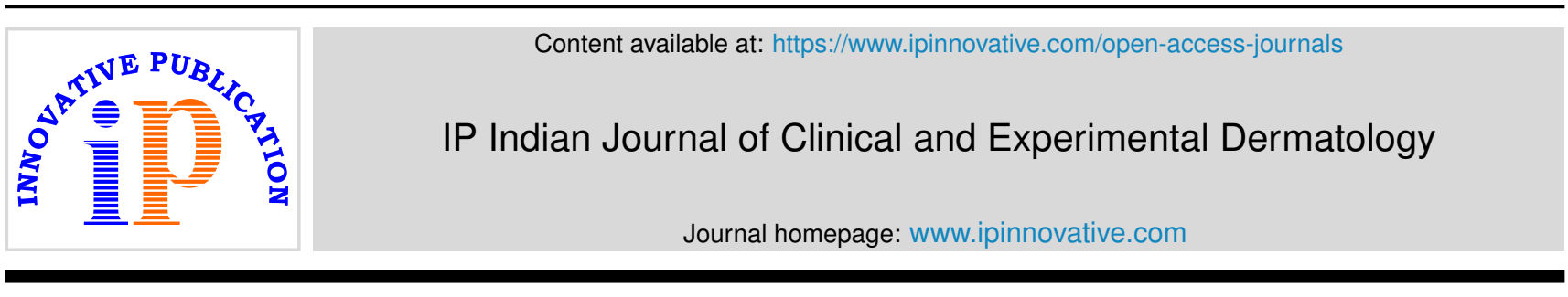

Original Research Article

\title{
Clinical evidence based nano crystalline silver dressing rationality, efficacy and strategy in extensive burn patients survival
}

\author{
Sudhir Singh ${ }^{1, *}$ \\ ${ }^{1}$ Dept. of Plastic Surgery, Getwell Hospital, Varanasi, Uttar Pradesh, India
}

\section{A R T I C L E I N F O}

Article history:

Received 11-04-2020

Accepted 22-07-2020

Available online 03-10-2020

\section{Keywords:}

Extensive burns

Nano crystalline silver

Acticoat

SSD

Bacteriophage

Collagen

Skin tempII

\begin{abstract}
A B S T R A C T
Extensive burns of more than 50\% have high mortality and those over $90 \%$ have almost nil survival rate. All resuscitative measures fail as patient gets infected leading to burn wound sepsis causing septicemia and leading to mortality as the end clinical result. So we need clinically evidenced and rationally based burn dressing strategy to increase extensive burn patient survival. This is random retrospective selection of five patients in each two groups from second degree burn patients of more than 50 percent treated by collagen in one group and other by Nanocrystalline Silver dressings and observed for clinical evidence of patients survival keeping all resuscitative and treatment modalities as standard treatment protocol in all cases. The nano crystalline silver dressing is cost effective, rational and evidence based strategy. It is easy to use, has powerful anti bacterial effect, decreased frequency of dressing changes, shortened time of wound cleaning and painless dressing. It helps make the wound sterile for further treatment within a week. It is a great weapon in the hand of Burn Surgeon for rapid and better recovery of patients. This nano crystalline sustained release silver dressings are best suited to take care of burn wounds of more than $50 \%$. Bacteriophages treatment is reserved for multiple drug resistant bacteria and had good recovery.
\end{abstract}

(C) 2020 Published by Innovative Publication. This is an open access article under the CC BY-NC license (https://creativecommons.org/licenses/by-nc/4.0/)

\section{Introduction}

There are many old burn wound dressings like honey, potato peel, banana leaves, alo-vera juice, collagen applications, soframycin ointment and of course even the traditional silver sulfadiazine cream. However the clinical evidence we get is that they are not helping in survival of extensive burn patients of more than fifty percent surface area even in second degree burns. Extensive burns of more than 50\% have high mortality and those over $90 \%$ have almost nil survival rate. All resuscitative measures fail as patient gets infected leading to burn wound sepsis causing septicemia and leading to mortality as the end clinical result. So we need clinically evidenced and rationally based burn dressing strategy to increase extensive burn patient survival.

\footnotetext{
* Corresponding author.

E-mail address: s.sulekha@gmail.com (S. Singh).
}

\section{Materials and Methods}

This is random retrospective selection of five patients in each two groups from second degree burn patients of more than 50 percent treated by collagen in one group and other by Nanocrystalline Silver dressings and observed for clinical evidence of patients survival keeping all resuscitative and treatment modalities as standard treatment protocol in all cases. Here we preferred using Skin Temp II Collagen which has major content of type I collagen (primary collagen synthesized by body during skin regeneration). The triple helical and banded fibrillar structure of collagen is preserved in this product and so it is identical to naturally occurring human collagen. I seldom use other dry or wet collagen as it is not so biocompatible due to its content of high abundance of type III collagen which is also sometimes immunogenic. For patients treated with nanocrystalline silver, we used Acticoat in which dressings were changed after 72 hours and sometimes Acticoat Flexi 7 in which dressings changed in seven days. 
Infact I tried to see the effect of bacteriophage in three cases of multiple drug resistant burn wound patient in extensive burn and had good recovery.

\subsection{Observations}

I had randomly selected retrospectively 5 patients from nanocrystalline silver dressing and collagen dressings group with in 3 years period and found that major bacteria of infection was E. Coli, streptoccoci, staph, pseudomonas, acetino- bacter species and klebsiella. In conventional day to day treatment we often if healing takes place it takes long duration even more than 10 to 16 weeks with more scarring and deformity. In collagen the result was good, duration of treatment shortened to 3-4 weeks and less scarring. Infection was controlled in all 5 cases with in 2 weeks. The nanocrystalline silver dressing is of choice as it controlled infection in all cases by 1 st week. Most patients have early recovery with in 2 weeks as average. So the nanocrytalline sustained release silver dressings are best suited to take care of burn wound of more than $50 \%$. [Nanocrystalline silver Patients Figure 1 A,B,C,D; Figure 2 A,B; Figure 3 A,B.] This is followed by collagen dressing which is less effective in killing bacteria but helps in regeneration of damaged skin barrier. [Collagen patients Figure 4 A,B,C; Figure 5 ; Figure 6 A,B; Figure 7] Both if used judiciously then give better survival even in $90 \%$ TBSA burn patients. They are great boon in the hands of plastic surgeon in saving megaburns. We have also tried to see and found encouraging role of bacteriophages in three cases of multiple drug resistant infected burns which were previously treated outside with two weeks of conventional dressing by Silver sulfadiazine cream. Bacteriophages took longer time ranging from two weeks to months in making wound good for reconstructive surgery like skin grafting [Bacteriophage treated patients Figure 8, Figure 9A,B; Figure 10A,B] [Table 1].

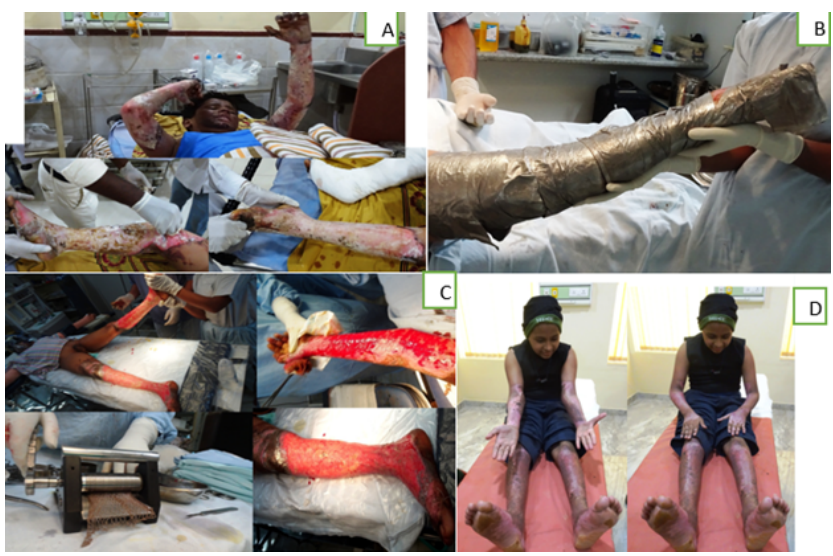

Fig. 1: Nanocryst. silver Pt. number 1 - A Extensive thermal burn, B dressing on all four limbs and face, C Skingrafting, D Healed burn wound.

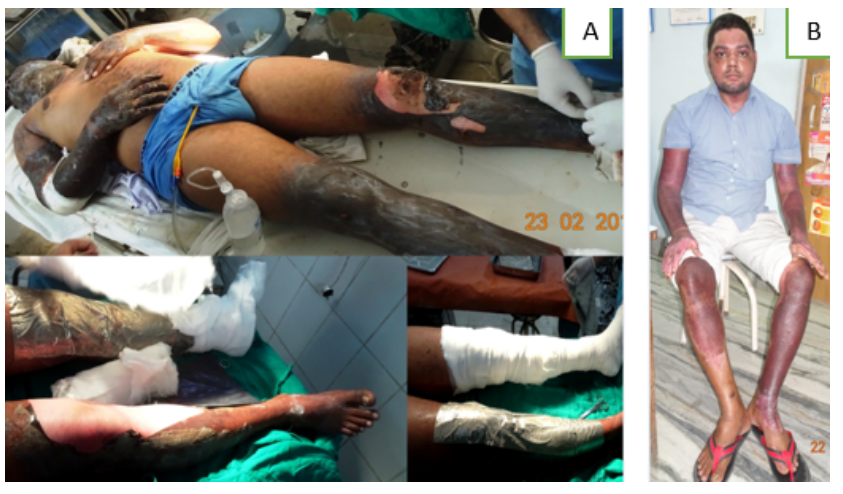

Fig. 2: Nanocryst. silver Pt number 2- A extensive burn, B Healed burn wound.

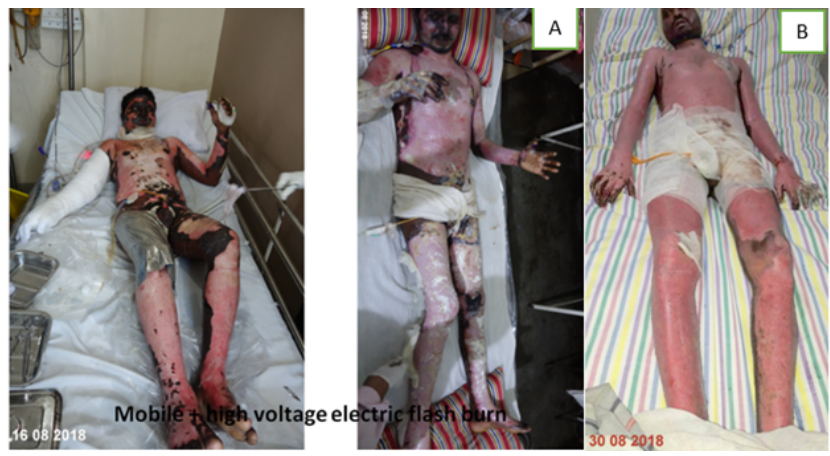

Fig. 3: Nanocryst. silver Pt. number 3- A Extensive flash burn, B healed 80 percent burn by acticoat.

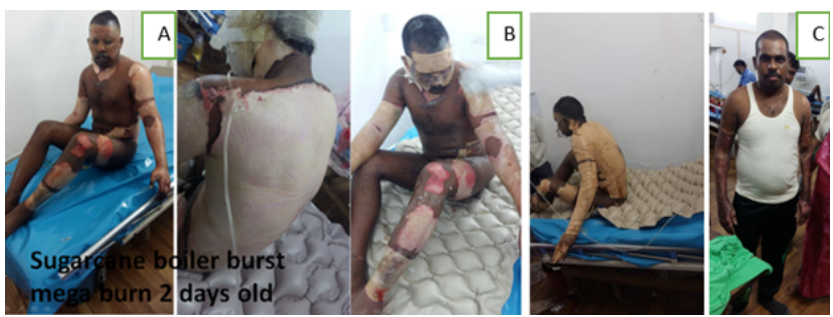

Fig. 4: Collagen Pt. number 1- A Boiler burst burn; B Collagen application; C Wound healed.

\section{Discussion}

The management of extensive burns is a very problematic subject. Solving this type of problem is hallmark of plastic surgeons. Extensive burns of more than $50 \%$ have high mortality and those over $90 \%$ have almost nil survival rate. ${ }^{1}$ In spite of all resuscitative fluid management, traditional burn wound care, proper antibiotics, immune enhancers, proper nutritional care, etc. Why is it so? The root cause is infection, causing burn wound sepsis, leading to septicemia, multiple organ failure, with ultimate mortality as a consequence. Prevention of infection is the main 
Table 1:

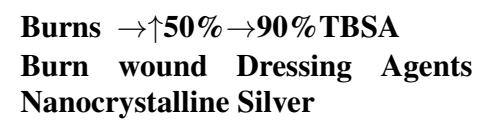

(1) 13yrs Old M Child

Thermal Burn

(2) 40yrs-M cracker

Thermal Burn

(3) Mobile electric

Flash -38yr. M

(4) Thermal Burn

Gas cylinder 40yr.F

(5) Thermal Burn

50yr. M

\section{Collagen Skin temp II}

(1) 32yrs. M Sugar cane

Boiler Burst

(2) Suicidal Burn

20yrs.F

(3) Electric Flash

neglected burn 22yrs.M

(4) HIV infected

Nurse 30yrs.F

(5) Thermal Burn

21 yr s. F

Bacteriophage (daily application) in 3 MDR cases in 20\%-70\% TBSA

(1) flame burn

$30 \% \mathrm{f}$

(2) Flame burn

10 days

$70 \% 15 \mathrm{yrs} / \mathrm{f}$

(3) Flame burn

$40 \% 35 \mathrm{yrs} / \mathrm{f}$
I Week

infected wound

Immediate

Immediate

3 day old

I week old

2 days

Immediate

2 mth.Old

1 Day Old

Immediate

\begin{tabular}{|c|c|}
\hline $\begin{array}{l}\text { E.coli } \\
\text { Klabsiella } \\
\text { staph } \\
\text { sterile }\end{array}$ & $\begin{array}{l}\text { Sterile in } \\
2 \text { weeks }\end{array}$ \\
\hline $\begin{array}{l}\text { A Citrobacter } \\
\text { Streptocolli } \\
\text { E.Coli }\end{array}$ & $\begin{array}{l}\text { Sterile } \\
\text { in } 2 \text { weeks } \\
\text { Sterile } \\
\text { in } 2 \text { weeks }\end{array}$ \\
\hline
\end{tabular}

Sterile in

I weeks

$\begin{array}{ll}\text { Staph+ } & \text { Sterile in } \\ \text { Pseudomonas } & 2 \text { weeks }\end{array}$

grafting 4 weeks

Grafting $\quad 4$ weeks

Conservative 2 weeks

Grafting 5 weeks

\section{Wound \\ healed by \\ surgery or \\ conservative}

Conservative 2-3 weeks

Sterile in one month

E.coli (11 days later)

Pseudomonas (6 days later)

Then Actinobact (7 days later)

Proteus Sterile in 10

Mirabilis days

Steptococci

Sterile in 10 days
Conservative 5 weeks

4 weeks

Conservative

Grafting $\quad 6$ weeks

Conservative 6 weeks

Conservative 5 weeks

Conservative 3 months

Conservative 3 weeks solution to decrease mortality in burn patients. Skin cover acts like the famous Mahabharata hero Karna's Armor, which protects the individual from onslaught of bacterial infection. If we prevent partial thickness burn wound from infection, the wound regenerates and skin cover appears within 2 to 3 weeks' time, healing the patient. Preventing infection in full thickness burn wound prepares the wound for successful skin grafting, plastic surgery with less mortality and early recovery. Bacteremia occurs in presence of burn wound due to any cause. In extensive burns, sepsis increases leading to septicemia and high mortality as discussed. Whenever the burn wound occurs it is sterile in the beginning. It gets infected within 24 hours by gm +ive bacteria like staphylococcus and later within a week by gm -ve bacteria like pseudomonas. The two dreadful bacterias like staphylococcus and pseudomonas are great enemies of burn specialists and detrimental to burn patients as they destroy or eat away or prevent the regeneration of skin. They have high role in septic burn wound pathogenicity. These days gm+ve bacteria are turning nasty and resistant 


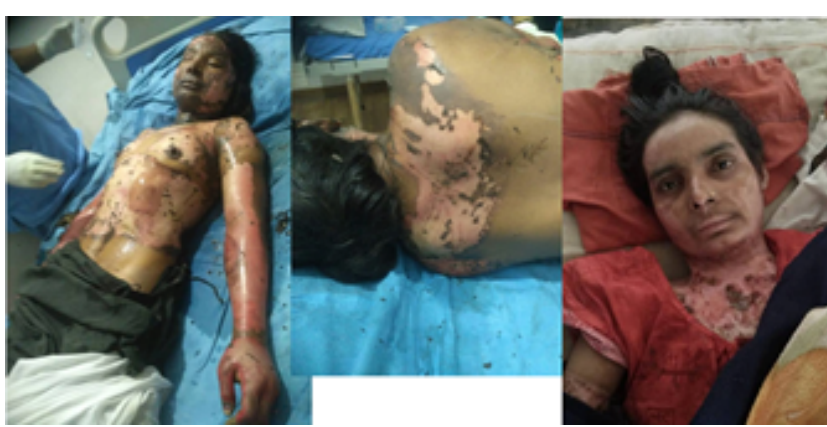

Fig. 5: Collagen Pt. number 2- suicidal burn.

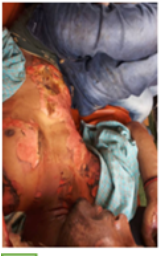

A
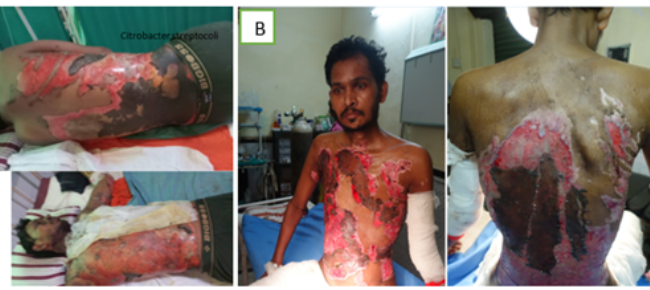

Fig. 6: Collagen Pt. number 3 - A Infected flash burn; B Infected flash burn treatment.

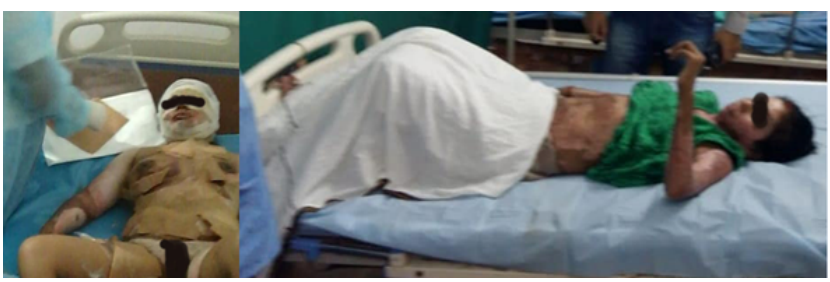

Fig. 7: Collagen Pt. number 4- burn with HIV

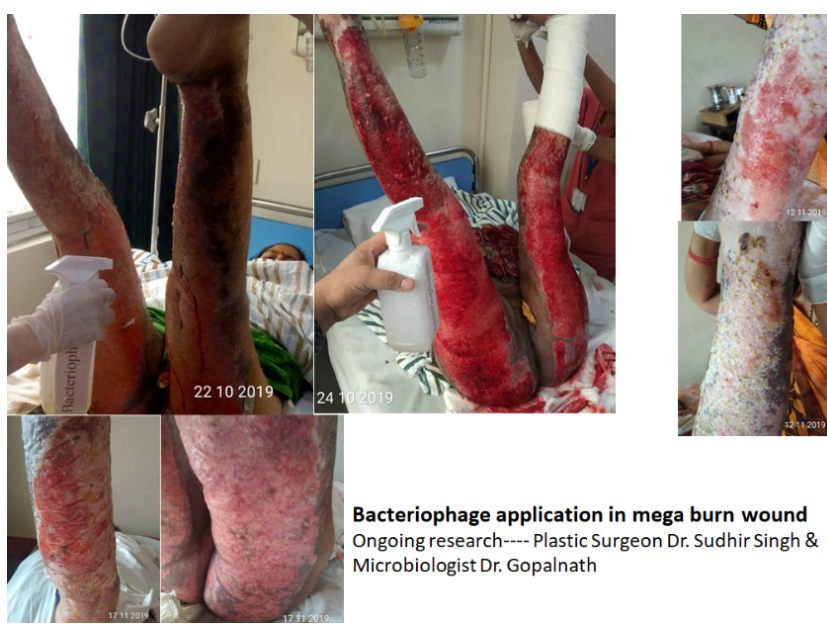

Fig. 8: Bacteriphage treated Pt. number 1
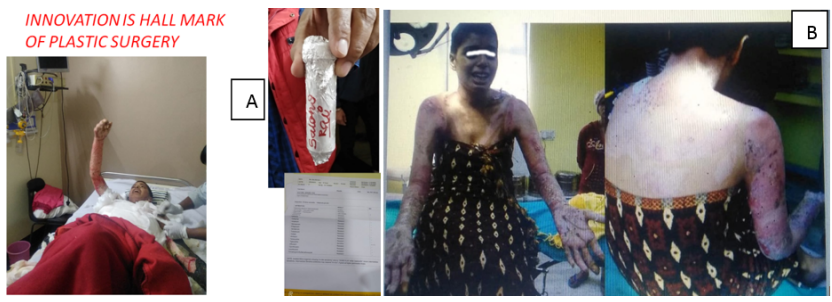

Fig. 9: Bacteriophage Pt. number 2- A on bacteriophage treatment; B Healed burn wound.

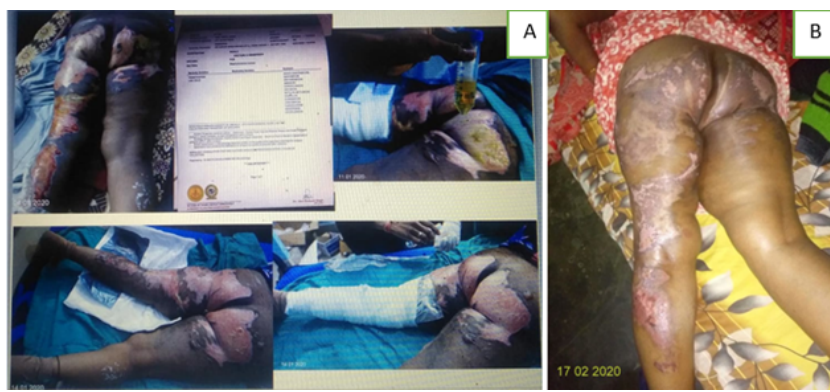

Fig. 10: Bacteriophage Pt. number 3- A on bacteriophage treatment; B Healed burn wound.

to antibiotics. Biofilms contribute to chronic infection. They are made of gelatinous proteinaceous material in which bacteria are entangled and protected from being penetrated by antibiotics. So they are difficult to eradicate with topical and systemic antibiotics. ${ }^{1-3}$

Research \& Design Laboratories and Research wings of pharma companies are more focusing on research of drugs for diabetes, cardio-vascular system, alzheimer's etc, but less focusing on evolution of newer antibiotics due to cost involvement and return. We had the golden period of antibiotics development during 1940 to 1970 and during 1980 and 1990, but for the last three decades no new antibiotic group has come into picture. This has coupled with emergence of multiple drug resistant pathogenic bacteria. We are slowly reaching the end of road in development of newer antibiotics and this will leave us to the mercy of infection causing high mortality by multiple drug resistant bacteria especially in burn wound sepsis. ${ }^{4}$ So what is the solution? We started working on bacteriophages which were discovered earlier to emergence of antibiotics but not much progress took place. They are human friendly viruses killing bacteria. We are having promising and encouraging results in managing burn wounds but still it is in our research phase and will take long time for common real clinical practice. Here we create in isolating in microbiology lab the specific viruses to kill MDR bacteria, e.g. T-4 bacteriophage for E coli. Bacteriophage may have future utility but at present we have to dig from past clinical experiences the best alternative to take care of burn wound. ${ }^{5,6}$ There were many old burn wound dressings like 
honey, potato peel, banana leaves, alo vera juice, collagen applications, but we found that silver is the best choice. ${ }^{7-13}$ Nothing can beat it.

It has been seen that once the whole army of Napoleon was decimated due to outbreak of cholera gastroenteritis but Napoleon and his nobles were saved because they used to drink or take food from silver utensils. Silver is an ancient water disinfectant.

So silver has centuries of proven antimicrobial activity. No resistance till date has been found. It is broad spectrum and kills all bacteria including multidrug resistant ones also. Silver cations destroy the bacteria by 3 mechanisms-

1. Destroy the bacterial cell membrane.

2. Destroy the cellular respiration.

3. Degenerates the genetic material of bacteria and other micro -organisms like fungi and viruses.

Also there is least potential of resistance development due to 3 targets of antibacterial action.Traditional delivery method of silver such as SSD cream or silver nitrate is not good but still being practiced in many areas due to ease of use and cheap cost. It is being used once daily which is irrational. The SSD cream releases almost all silver in very high quantity, i.e to the extent of $3000 \mathrm{ppm}$, and which acts only for 6 hours at the most. In that way per day at least 4 dressings are required which become cumbersome and wound is exposed to infective environment repeatedly which in turn increases more chance of infection. In fact to kill bacteria we just require 20-40 ppm of silver and here we are wasting high level of silver, i.e. about $3000 \mathrm{ppm}$ in once a day dressing which is wasted without use. Due to work constraint most burn surgeons follow once a day dressing with SSD leading to bad results. However I stress, Silver is nontoxic to human cells and all toxicity of SSD cream or silver nitrate is attributed to carriers like sulphadiazine and nitrate compounds.

So we need ionic silver dressings to get the full benefit of silver action to take care of the extensive burn wound sepsis. ${ }^{14,15}$ Normal silver crystals found in SSD cream are of 250-900nm but nano crystalline silver dressing material with sustained release silver have 10-22 nm diameter silver particles. The properties and behavior of a material changes as the particle size approaches that of individual atoms or molecules, and may represent a new state of solid matter. The smaller the size of nano crystalline silver, it provides a considerable increase in surface area for release of silver ions, resulting in rapid release of bactericidal levels of silver. In addition, the unique properties of the nano crystalline silver allows the release of other species of silver ions, which may contribute to the sustained antimicrobial activity. So nano crystals of silver are found to be extremely porous, with a greatly enhanced surface area per mass from which ionization and dissolution of silver ions can occur. This quality of material provides a rapid release of silver (i.e. quick kill within 30 minutes). Silver ions which are active ions to kill bacteria are released by all silver dressings but nano crystalline with 70-100 ppm which is more than required of 20-40 ppm are released and therefore the latter provides a greater kill rate of bacteria. In fact all silver dressings release silver ions at differing concentrations but nano crystalline silver is unique in that it also contains the silver atom species. ${ }^{16-21}$ Metallic silver does not normally dissolve in water but the $\mathrm{AgO}$ atoms in nano crystalline dressings are present in very small clusters (4-5 molecules) which allow it to be solubilized. As these clusters undergo chemical reactions with exudate additional Ag+ ions are released. It's like a backup battery to ensure the optimal release of Ag+ i.e. a similar analogy as to having a backup battery and this is why concentration of 70-100 ppm are released over extended time periods, i.e. up till 3-7 days at a stretch.

I should emphasize that nano crystalline silver dressings release 30 times less silver cations than other forms of silver such as $0.5 \%$ silver nitrate or SSD cream. However, more of the silver released is effective and release is sustained.

Nano crystalline silver dressing causes Log 5 reduction of bacteria within 30 minutes which is more than required Log 3 reduction for bactericidal effect. However SSD cream or other traditional silver dressings rarely approach Log 3 reduction of bacterial kill and so are more of bacteriostatic in effect. Survival rates are highest by far in the uninfected and sustained release nano crystalline silver dressing treated burn wounds. On the infected control and silver nitrate covered wound survival rates are low - mainly due to rapid inactivation of silver ions released from silver nitrate or SSD cream at the wound surface. I have even shown one case of more than $80 \%$ electric flash burn wound healed in 2 weeks time by nano crystalline silver dressing as we have prevented infection effectively and so proper regeneration of skin has taken place and the patient has healed.

Nano crystalline silver dressing reduces the inflammatory processes and promotes wound healing and is less toxic than other forms of silver dressings due to prolonged release of appropriate bactericidal concentration of silver on the wound bed. ${ }^{22-26}$

\section{Conclusion}

The nano crystalline silver dressing is cost effective, rational and evidence based strategy. ${ }^{27}$ It is easy to use, has powerful anti bacterial effect, decreased frequency of dressing changes, shortened time of wound cleaning and painless dressing. It helps to make the wound sterile for further treatment within a week. It is a great weapon in the hand of Burn Surgeon for rapid and better recovery of patients. How ever this is small retrospective clinical study of extensive burn wound effective dressing relying on clinical evidence of patient recovery. This nano crystalline sustained release silver dressings are best suited to take care 
of burn wounds of more than 50\%. However SUPERBUGS will be taken care by BACTERIOPHAGE in Future. We hope that sooner or later the role of bacteriophage will soon be established by further study in multiple drug resistant infected burn patients because of extensive and prolonged use of conventional SSD cream treatment. It can be inferred that use of nanocrytalline silver from the begining may decrease the necessity of bacteriophage in resistant infected burn patients treated by SSD conventional dressing for prolonged duration.

\section{Source of Funding}

None.

\section{Conflict of Interest}

None.

\section{References}

1. Wright J, Lam K, Burrell R. Wound management in an era of increasing bacterial antibiotic resistance: a role for topical silver. Am J Infect Control. 1998;26(6):572-7.

2. Wright JB, Lam K, Buret AG, Olson ME, Burrell RE. Early healing events in a porcine model of contaminated wounds: effects of nanocrystalline silver on matrix metalloproteinases, cell apoptosis, and healing. Wound Repair Regen. 2002;10(3):141-51.

3. Wright B, Lam K, Olsen M. Is antimicrobial efficacy sufficient? A question concerning the benefits of new dressings. Wounds: A Compendium of. Clin Res Pract. 2003;15:133-47.

4. Pirnay JP, Vos DD, Cochez C, Bilocq F, Pirson J, Struelens M, et al. Molecular Epidemiology of Pseudomonas aeruginosa Colonization in a Burn Unit: Persistence of a Multidrug-Resistant Clone and a Silver Sulfadiazine-Resistant Clone. J Clin Microbiol. 2003;41(3):11921202.

5. Rose T. Experimental phage therapy of burn wound infection: Difficult first steps. Int J Burns Trauma. 2014;4(2):66-73.

6. Rios AC, Moutinho CG, Pinto FC, Fiol FSD, Jozala A, Chaud MV, et al. Alternatives to overcoming bacterial resistances: State-of-theart. Microbiological Res. 2016;191:51-80.

7. Thomas S. An in vitro analysis of the antimicrobial properties of 10 silver-containing dressings. J Wound Care. 2003;12:305-9.

8. Thomas S. A comparison of the antimicrobial effects of four silvercontaining dressings on three organisms. $J$ Wound Care. 2003;12:101-7.

9. Woodward M. Silver dressings in wound healing: what is the evidence? Primary Intention. 2005;13:153-60.

10. Wright JB, Lam K, Hansen D, Burrell RE. Efficacy of topical silver against fungal burn wound pathogens. Am J Infect Control. 1999;27(4):344-50.

11. Heggers J, Goodheart RE, Washington J, McCoy L, Carino E, Dang T, et al. Therapeutic Efficacy of Three Silver Dressings in an Infected Animal Model. Burn Care Rehabil. 2005;26(1):53-6.

12. Ülkür E, Oncul O, Karagoz H, Yeniz E, Çeliköz B. Comparison of silver-coated dressing (Acticoat ${ }^{\mathrm{TM}}$ ), chlorhexidine acetate $0.5 \%$ (Bactigrass ${ }^{\circledR}$ ), and fusidic acid $2 \%$ (Fucidin ${ }^{\circledR}$ ) for topical antibacterial effect in methicillin-resistant Staphylococci-contaminated, full-skin thickness rat burn wounds. Burns. 2005;31(7):874-7.

13. Ulkur U, Oncul O, Karagoz H. Comparison of silver-coated dressing (ActicoatTM), chlorhexidine acetate 0.5\% (BactigrassR), and sulfadiazine $1 \%$ (Silverdin) for topical antibacterial effect in Pseudomonas aeruginosa contaminated, full thickness burn wound in rats. J Burn Care Rehabil. 2005;26:430-3.

14. Lansdown ABG, Williams A, Chandler S, Benfield S. Silver absorption and antibacterial efficacy of silver dressings. $J$ Wound Care. 2005;14(4):155-60.

15. Gago M. A comparision of three silver containing dressings in the treatment of infected. Wounds. 2008;20(10):273-8.

16. Yin HQ, Langford R, Burrell RE. Comparative Evaluation of the Antimicrobial Activity of ACTICOAT Antimicrobial Barrier Dressing. J Burn Care Rehabil. 1999;20(3):195-9.

17. Supp A, Needy A, Supp D. Evaluation of cytotoxicity and antimicrobial activity of Acticoat burn dressing for management of microbial contamination in cultured skin substitutes grafted to anthymic mice. J Burn Care Rehabil. 2005;26(3):238-46.

18. Innes ME, Umraw N, Fish JS, Gomez M, Cartotto RC. The use of silver coated dressings on donor site wounds: a prospective, controlled matched pair study. Burns. 2001;27(6):621-7.

19. Dunn K, Edwards-Jones V. The role of Acticoat ${ }^{\mathrm{TM}}$ with nanocrystalline silver in the management of burns. Burns. 2004;30:S1-9.

20. Kirshner R. Matrix metalloproteinases in normal and impaired wound healing: A potential role of nanocrystalline silver. Wounds: A Compendium of. Clin Res Pract. 2002;13:4-14.

21. Rustogi R, Mill J, Fraser JF, Kimble RM. The use of Acticoat ${ }^{\mathrm{TM}}$ in neonatal burns. Burns. 2005;31(7):878-82.

22. Sibbald R, Raphael S, Rothman A. Open label pilot study of prolonged release nanocrystalline silver dressing (Acticoat 7): reduction of bacterial burden treatment in the treatment of chronic venous leg ulcers. Wound Repair Regen. 2005;13:35.

23. Tredget EE, Shankowsky HA, Groeneveld A, Burrell R. A MatchedPair, Randomized Study Evaluating the Efficacy and Safety of Acticoat* Silver-Coated Dressing for the Treatment of Burn Wounds. J Burn Care Rehabil. 1998;19(6):531-7.

24. Varas R, Keefe T, Namia N. A prospective, randomized trial of Acticoat versus silver sulfadiazine in the treatment of partial thickness burns: which method is less painful? J Burn Care Rehabil. 2005;26:344-7.

25. Voight D, Paul C. The use of Acticoat as silver impregnated Telfa dressings in a Regional burn and wound care center: the clinicians view. Wounds: A Compendium of. Clin Res Pract. 2001;13:11-23.

26. Demling RH, Santi LD. The rate of re-epithelialization across meshed skin grafts is increased with exposure to silver. Burns 2002;28(3):264-6.

27. Nherera L, Trueman P, Roberts C, Berg L. Cost-effectiveness analysis of silver delivery approaches in the management of partial-thickness burns. Ann Burns Fire Disasters. 2019;32(3):222-6.

\section{Author biography}

Sudhir Singh Honorary IMA Professor \& Sr. Consultant Plastic Surgery

Cite this article: Singh S. Clinical evidence based nano crystalline silver dressing rationality, efficacy and strategy in extensive burn patients survival. IP Indian J Clin Exp Dermatol 2020;6(3):268-273. 